\title{
Screening for Qualitative Status of Five Popular Marketed Brands of Tea Produced in Bangladesh
}

\author{
K M Mesbaul Alam", R. Ahmed, C. Rashid, M. S. Uddin, M. A. M. Chowdhury \\ Department of Botany, University of Chittagong, Bangladesh
}

Copyright (C) 2015 Horizon Research Publishing All rights reserved.

\begin{abstract}
Five different popular marketed brands of tea produced in Bangladesh viz; Tetley-Premium, Lipton-Taaza, Finlay-Premium, HRC-Clevedon, Ispahani-Blender's choice were studied before expiry dates to evaluate their status of qualitative parameters viz; Caffeine, Total Polyphenol Content (TPC), Theaflavin (TF), Thearubigin (TR), Highly Polymerized Substances (HPS), Total Liquor Colour (TLC), Briskness Index (BI) and Colour Index (CI). All the studied parameters were found to have been varied with brands. The values of caffeine and TPC were found to be varied from $2.65 \%$ (Finlay-Premium) to $3.28 \%$ (Tetley-Premium) and $24.58 \%$ (Lipton-Taaza) to $12.76 \%$ (Tetley-Premium) respectively. Similarly, the estimated values of TF, TR and TLC were detected to be maximum in Lipton-Taaza tea but maximum HPS was in Finlay-Premium tea whereas minimum TF and TLC was in Tetley-Premium tea and minimum TR and HPS was in HRC-Clevedon tea. In contrast, $\mathrm{BI}$ and $\mathrm{Cl}$ were found to be the highest in Ispahani-Blender's choice and HRC-Clevedon tea respectively and the lowest in Tetley-Premium tea. The present study concludes that the Lipton-Taaza tea is superior over the other brands in respect to qualitative status and all the studied brands may, therefore, be ranked as: Lipton-Taaza $>$ Finlay-Premium $>$ Ispahani-Blender's choice $>$ HRC-Clevedon $>$ Tetley-premium.
\end{abstract}

Keywords Screening, Qualitative Status, Tea, Brands, Bangladesh

\section{Introduction}

Tea is an aqueous infusion of dried leaves of the plant Camellia sinensis (L.) Kuntze and is the most popular beverage consumed by world-wide human society [1]. The study of tea chemistry may be said to have begun with the isolation of the alkaloid caffeine from tea in 1827 [2]. Tea has been valued historically for its caffeine content, which is between 2 and $5 \%(\mathrm{w} / \mathrm{w})$ depending on variety. High caffeine content in fresh leaf may be one of the important factors ensuring good quality of the resulting black tea [3]. Caffeine is regarded as an important constituent of tea, bestowing mood and cognitive-enhancing properties $[4,5]$.

Polyphenols are the active components responsible for the beneficial effects of drinking green tea [6]. A large number of polyphenol derivatives have been identified in various types of green (non-fermented), oolong (semi-fermented) and black (fully-fermented by oxidizing enzyme) teas [7]. These polyphenols account for $20-35 \%(w / w)$ of the dry tea $[8,9]$, thus representing a significant proportion of the tea constituents.

Polyphenols occurring in black tea usually consist of residual green tea polyphenols such as catechins [10,11], flavonols [10,12] and oxidation products of green tea polyphenols such as theaflavins and thearubigins. Most of the catechins and their gallates undergo known enzymatic oxidation to form more polymeric polyphenols that are characteristic of black tea, namely theaflavins and thearubigins. Theaflavins are known as fermentation products and provide a bright, yellowish appearance to the beverage and have long been positively correlated with the quality and market value of black tea $[13,14,15]$. Theaflavin with a formula $\mathrm{C}_{29} \mathrm{H}_{24} \mathrm{O}_{12}$ [16] may contain 3.5 moles of water in the crystallization [17]. The content of total theaflavins in black tea does not usually exceed $2 \%$ and can be as low as $0.3 \%$ [18], whereas Graham [19] reported that theaflavins ranged $1.5-2.5 \%$ in the dry leaf.

Further oxidation of theaflavins produces a group of brown pigments called thearubigins $[13,15]$. The content of theaflavins is far less than that of thearubigins in black tea ( 6 to $18 \%$ of dry weight), but theaflavins are of primary importance to tea quality, since they impart the specific bright and vivid colour to the liquor; and further, the ratio of theaflavins to thearubigins has been found to be responsible for the strength of the tea liquor [4].

The thearubigins, on reaction with TF and proteins, form complex highly polymerized substances (HPS). Highly polymerized substances increase the colour of the brew. Total liquor colour (TLC) is the measure of brightness of the infusion [20].

The whole tea year in Bangladesh is divided on the basis of production and plucking intensity into three plucking periods viz; increasing (May-July), peak (August- October) and decreasing (November-January). Pluckable twigs were graded as high (high caffeine and medium polyphenol), medium (medium caffeine and high polyphenol) and low (low caffeine and low polyphenol) quality tea on the basis of quantity of caffeine and polyphenol on increasing, peak and decreasing periods respectively (Alam and Chowdhury, 
2007). So far the literature review is concerned; only a comparative study on the qualitative status of ten major marketed brands of tea of Bangladesh was done by Alam et al. [21]. With this view in mind, in addition to these ten brands of tea, a laboratory experiment was done to screen out the comparative status of quality parameters viz; caffeine, TPC, TF, TR, HPS, TLC contents as well as briskness and colour indices in five popular marketed brands of tea of Bangladesh.

\section{Materials and Methods}

Five different types of brand tea namely Tetley-Premium, Lipton-Taaza, Finlay-Premium, HRC-Clevedon, Ispahani-Blender's choice were collected from the local market at a time.

\section{Determination of caffeine content in tea samples}

Preparation of stock solution

$5 \mathrm{~g}$ tea sample was taken in a $500 \mathrm{ml}$ conical flask. $10 \mathrm{~g}$ crystal of $\mathrm{MgO}$ and $200 \mathrm{ml}$ of distilled water were added to the sample simultaneously. The mixture was then warmed in the water bath maintained at $40^{\circ} \mathrm{C}$ for $2 \mathrm{hrs}$. Then, it was fettered through whatman- 42 and the filtrate was collected in $200 \mathrm{ml}$ volumetric flask. The volume of the filtrate was made up to the mark by adding distilled water and used as stock solution.

\section{Extraction}

$200 \mathrm{ml}$ of filtrate was taken in $500 \mathrm{ml}$ conical flask and $20 \mathrm{ml}$ diluted $\mathrm{H}_{2} \mathrm{SO}_{4}\left(2 \mathrm{ml}\right.$ conc. $\mathrm{H}_{2} \mathrm{SO}_{4}+18 \mathrm{ml}$ dist. $\left.\mathrm{H}_{2} \mathrm{O}\right)$ was added. This mixture of $220 \mathrm{ml}$ volume was then heated; at temperature $90^{\circ} \mathrm{C} \pm 2{ }^{\circ} \mathrm{C}$ maintained in a water bath and reduced the volume of the mixture to about $50 \mathrm{ml}$. The concentrated mixture was again filtered through whatman- 42 and collected in the separating funnel. Then $20 \mathrm{ml}$ chloroform was added with the filtrate in the separating funnel and shaken well for 20 times. The separating funnel was then kept undisturbed on a stand for 10 minutes. The washed chloroform from the bottom of the separating funnel was collected in $50 \mathrm{ml}$ conical flask. The same filtrate was then washed thoroughly with different volumes (viz, 20, 15, 10 and $5 \mathrm{ml}$ ) of chloroform and the total volume of the collected chloroform was washed with $5 \mathrm{ml} 1 \% \mathrm{KOH}$ in a clean separating funnel and was collected in a $50 \mathrm{ml}$ oven dried conical flask which was previously weighed.

\section{Procedure}

Each conical flask was cleaned; dried (oven-dry); marked and weighed in electric balance before receiving the washed chloroform. After receiving the chloroform the respective conical flask was kept in electric oven at $70^{\circ} \mathrm{C}$ for complete dryness. The weight of the dried concial flask was recorded in electric balance.

\section{Calculation}

Caffeine $=(\mathrm{S}-\mathrm{B}) \mathrm{mg} / \mathrm{g}$

Where, $\mathrm{S}=$ weight of conical flask with caffeine after dryness, $\mathrm{B}=$ weight of conical flask before filtrate collection [22].

\section{Determination of Polyphenol in tea samples}

Preparation of 1000 ppm tannic acid stock solution

$1 \mathrm{~g}$ tannic acid was taken in a $1000 \mathrm{ml}$ volumetric flask. Then, small amount of distilled water was added and shaken well to dissolve tannic acid. Then, the volume was made up to the mark with the addition of distilled water. This solution was used as $1000 \mathrm{ppm}$ stock solution. From 1000ppm stock solution 1ppm, 2ppm, 3ppm, 4ppm \& 5ppm solution were prepared.

\section{Procedure}

$100 \mathrm{mg}$ of tea sample was boiled in a water bath with 100 $\mathrm{ml}$ of water for 30 minutes and filtered. $0.2 \mathrm{ml}$ of the sample solution and $5 \mathrm{ml}$ of the reagent $\left(100 \mathrm{mg}\right.$ of $\mathrm{FeSO}_{4} \cdot 7 \mathrm{H}_{2} \mathrm{O}$ and $500 \mathrm{mg}$ of Rochelle salt in $100 \mathrm{ml}$ of water) were taken in a $25 \mathrm{ml}$ volumetric flask and filled to the mark with Sorensen's phosphate buffer of $\mathrm{pH}$ 7.5. Then the absorbance was measured at $540 \mathrm{~nm}$ against a blank solution substituting water for the reagent and the amount of polyphenol was determined using the correction factor (cf) obtained from the calibration curve made by using different concentration of tannic acid [23].

Black tea samples were analyzed for TF, TPC, TR, HPS and Total Liquor Colour (TLC) by following the method reported by Thanaraj and Seshadri [24]. The briskness and colour indices were worked out as suggested by Ramaswamy [25], [briskness index $(\mathrm{BI})=(\mathrm{TFs} \times 100) /(\mathrm{TF}+$ Caffeine $)$ and colour index $(\mathrm{CI})=(\mathrm{TFs} \times 100) /(\mathrm{TR}+\mathrm{HPS})]$. Every data was the mean value of three samples (bought one time and split into three samples) and statistical analysis was done using the computer progamme (SPSS). Means were compared using the least significant difference test (LSD) at $0.05[26]$.

\section{Results and Discussion}

The results as shown in Table 1 exhibit that caffeine content was found to vary with brands of tea. The maximum value of caffeine content was found to be $3.28 \%$ (Finlay-premium) and the minimum value was found to be $2.65 \%$ (Tetley-premium) and showed the following sequence as Finlay-premium $>$ Lipton-Taaza $>$ HRC-Clevedon $>$ Ispahani-Blender's Choice > Tetley-premium. Tea generally contains caffeine at about $1-5 \%$ of its dry weight [27]. The average range of caffeine content in Bangladesh tea is 3.3-4.8\% [28, 29]. Caffeine content varies with agrotypes, plucking periods and commercial brands [21]. Maximum caffeine content is found in increasing plucking period (May-July) and minimum in decreasing plucking period (November-January) [30]. It is also reported [30] that caffeine content of Bangladesh tea was found to vary from $3.87 \%$ to $4.67 \%, 2.53 \%$ to $3.87 \%$ and $1.73 \%$ to $2.67 \%$ in increasing, peak and decreasing plucking periods respectively. So it is evident from the result that the caffeine contents of present experiment can be 
ranked as medium in respect to Bangladesh standard and except the Tetley tea, all the studied brands might have been harvested in peak plucking period (August-October). Accordingly, Tetley tea might have been harvested in decreasing plucking period (November-January).

The results as shown in Table 1 also exhibit that total polyphenol content (TPC), theaflavin (TF), thearubigin (TR), highly polymerized substances (HPS) and total liquor colour (TLC) content were found to be varied with brands of tea. Maximum amount of total polyphenol content (TPC) was estimated to be $24.58 \%$ in Lipton-Taaza and minimum was $12.76 \%$ in Tetley-Premium tea. Total polyphenol content followed the sequence as

Lipton-Taaza $>$ Finlay-Premium $>$ Ispahani-Blender's Choice $>$ HRC-Clevedon $>$ Tetley-Premium. Tea generally contains $15-18 \%$ of polyphenol [31]. The range of total polyphenol content in Bangladesh tea is $22-31 \%$ [28,29]. It is also reported that total polyphenol content of Bangladesh tea ranged from $20.79 \%$ to $23.57 \%, 24.60 \%$ to $31.54 \%, 6.58 \%$ to $10.74 \%$ in increasing, peak and decreasing plucking periods respectively [30]. So present experiment reveals that total polyphenol content of all the five studied brands are reasonable and comparable with Bangladesh standard. The result also indicates that except the Tetley tea, the remaining four studied brands might have been manufactured from the tea shoots plucked in peak plucking period (August-October) and that of Tetley tea in decreasing plucking period (November-January).

The highest value of TF content was found to be $1.025 \%$ (Lipton-Taaza) and the lowest value was found to be $0.875 \%$ (Tetley) and showed the following sequence as Lipton-Taaza $>$ Finlay-Premium $>$ Ispahani Blender's Choice $>$ HRC-Clevedon $>$ Tetley-Premium. Maximum TR was determined to be $5.725 \%$ (Lipton Taaza) and minimum was determined to be $4.282 \%$ (HRC-Clevedon) and showed the following sequence as Lipton-Taaza $>$ Ispahani-Blender's Choice $>$ Finlay-Premium $>$ Tetley-Premium $>$

HRC-Clevedon.

The highest amount of HPS content was observed to be $6.253 \%$ (Finlay-Premium) and the lowest amount was observed to be $41.21 \%$ (HRC-Clevedon) and showed the following sequence as Finlay-Premium $>$ Lipton-Taaza $>$ Ispahani-Blender's Choice>

Tetley-Premium $>$ HRC-Clevedon. Maximum TLC was estimated to be 3.440 (Lipton-Taaza) and minimum was estimated to be 2.560 (Tetley-Premium) and followed the sequence as Lipton-Taaza $>$ Finlay-Premium $>$ Ispahani-Blender's Choice $>$ HRC-Clevedon> Tetley-Premium.

Table 1. Caffeine, TPC, TF, TR, HPS and TLC contents in five popular marketed brand teas of Bangladesh.

\begin{tabular}{|c|c|c|c|c|c|c|}
\hline Brand & Caffeine (\%) & TPC (\%) & TF (\%) & TR (\%) & HPS (\%) & TLC \\
\hline Tetley-Premium & 2.65 & 12.76 & 0.875 & 4.564 & 4.765 & 2.560 \\
\hline Lipton-Taaza & 3.22 & 24.58 & 1.025 & 5.725 & 5.825 & 3.440 \\
\hline Finlay-Premium & 3.28 & 22.32 & 1.010 & 5.218 & 6.253 & 3.215 \\
\hline HRC-Clevedon & 3.17 & 20.25 & 0.920 & 4.282 & 4.121 & 2.950 \\
\hline Ispahani-BC & 3.05 & 21.46 & 1.005 & 5.545 & 5.458 & 3.020 \\
\hline LSD at 0.05 & 0.282 & 0.478 & 0.081 & 0.215 & 0.129 & 0.330 \\
\hline
\end{tabular}

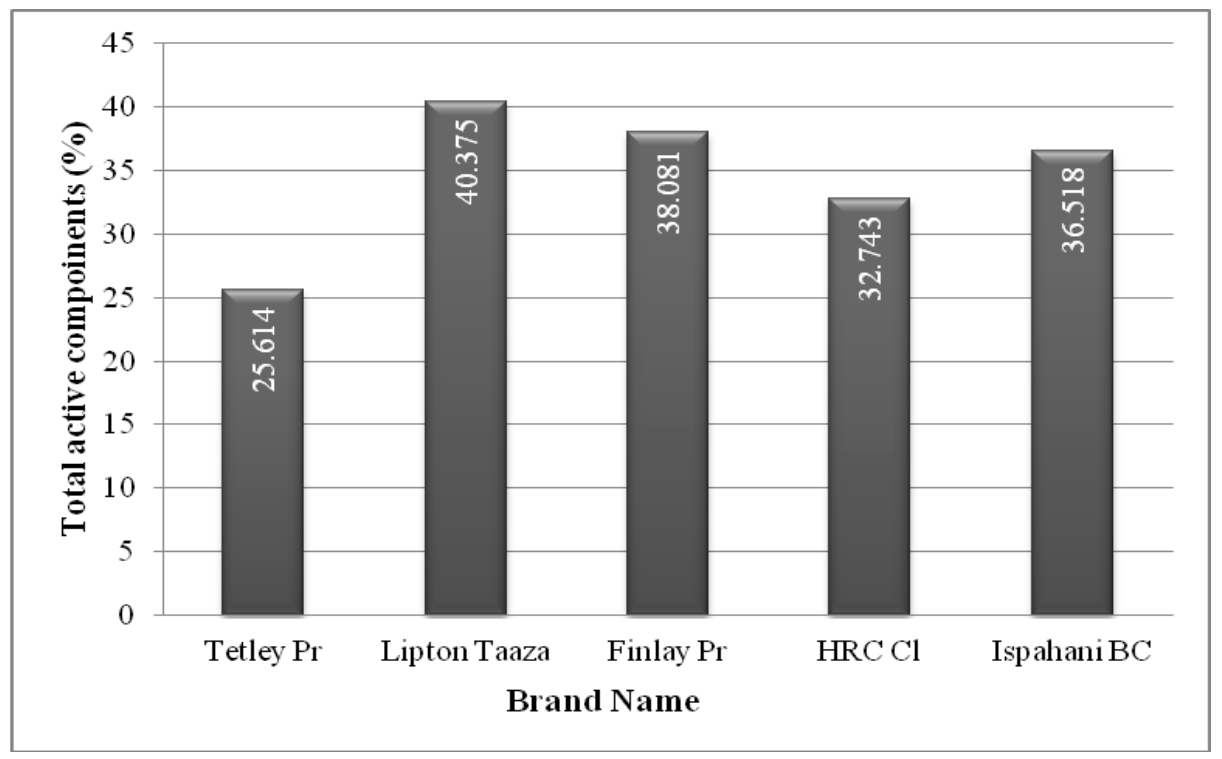

Figure 1. Total contents of quality parameters (Caffeine, TPC, TF, TR and HPS) in five popular marketed brand teas of Bangladesh. 


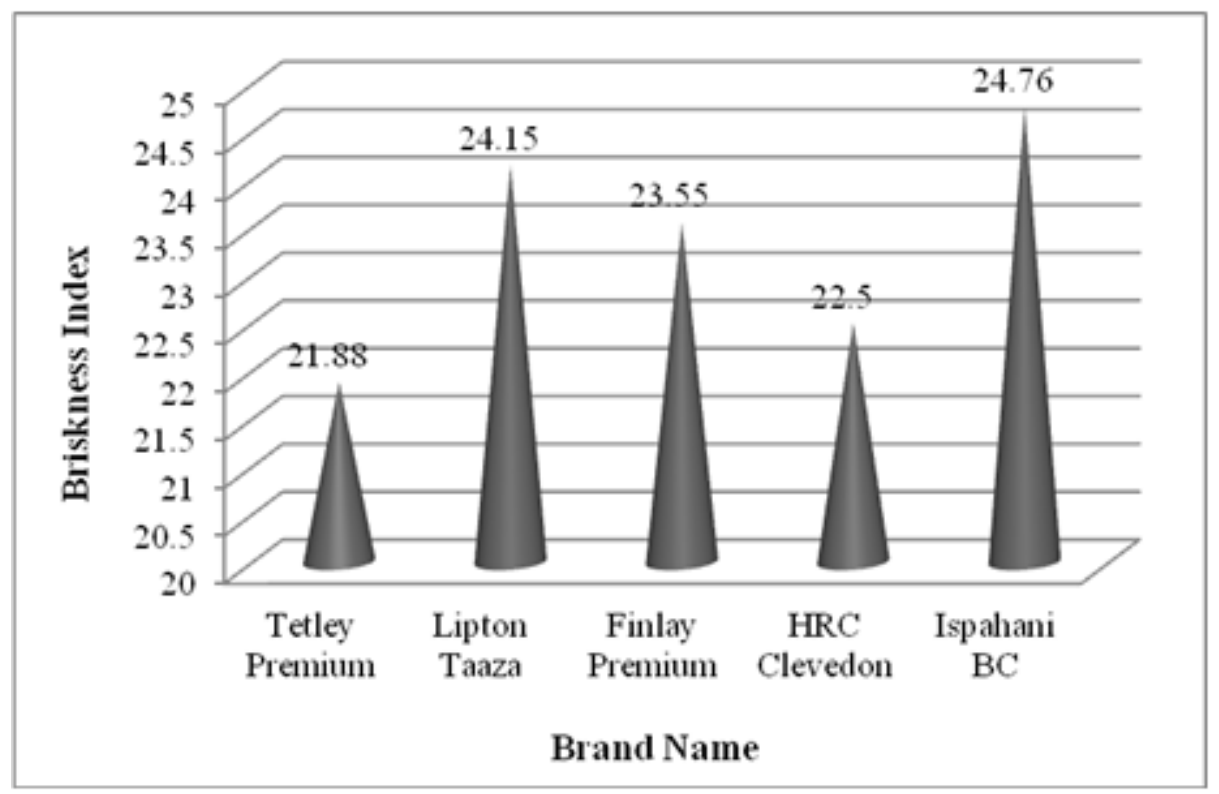

Figure 2. Briskness index of five popular marketed brand teas of Bangladesh.

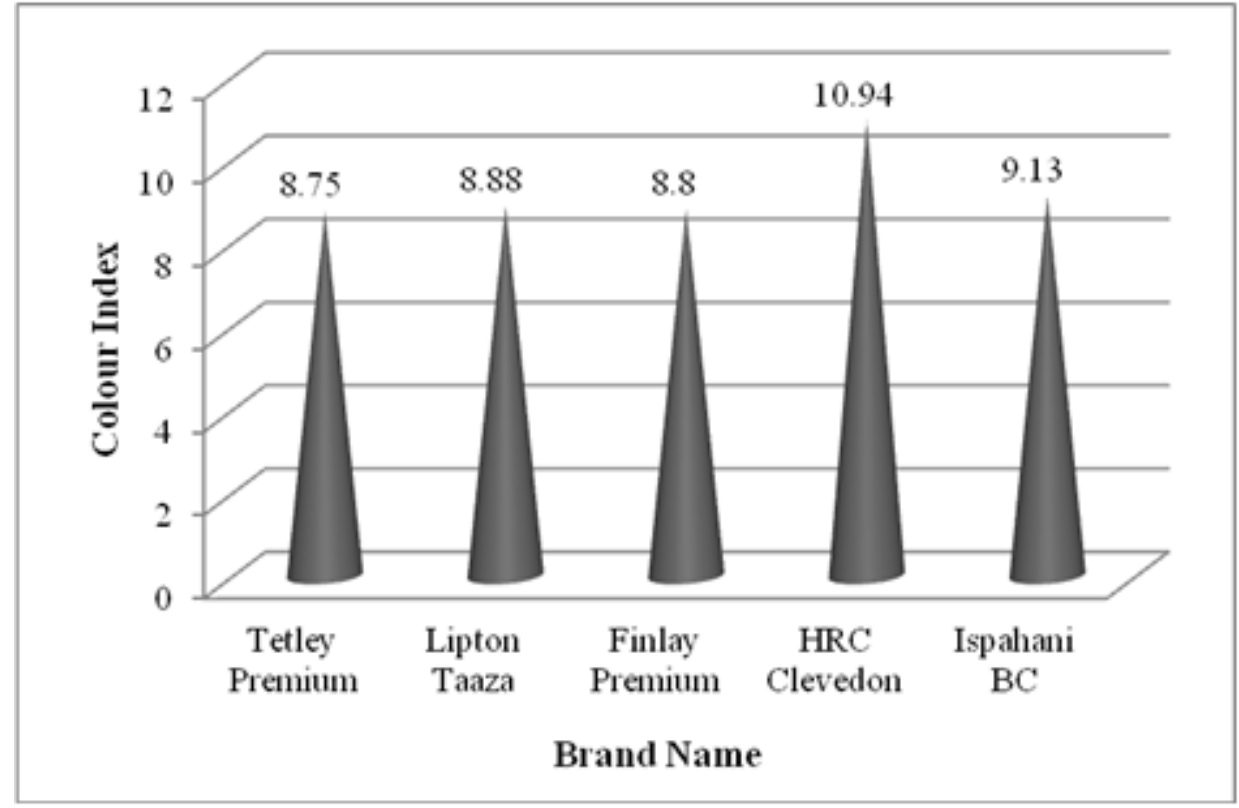

Figure 3. Colour index of five popular marketed brand teas of Bangladesh.

In case of Bangladesh tea, it is reported that in the tea of bud and first internode the average caffeine, TPC, TF, TR, HPS and TLC contents were determined as $4.23 \%, 28.52 \%$, $1.056 \%, 5.730 \%, 3.444 \%$ and 2.30 respectively. But all of these components trends to be decreased downward significantly in the tea of four leaves and a bud with fifth internode whilst the contents were determined as $1.54 \%$, $10.32 \%, 0.733 \%, 4.127 \%, 3.956 \%$ and 1.631 respectively [32].

It is also suggested that plucking standard should be maintained up to two leaves and a bud including third internode for the production of teas having proper caffeine, TPC, TF, TR, HPS and TLC contents to optimize the black tea quality [32].

Hence, from the results of this experiment, it can be assumed that TF content of all the studied brands of teas were not up to the mark in comparison to Bangladesh standard. Every brand possessed low TF, TR, HPS and TLC contents which were supposed to be obtained from four leaves and a bud with fifth internode and downward plucking. So, all the studied brands might not have maintained plucking standard as well as manufacturing awareness.

It is evident from the result as shown in Fig. 2 that the highest value of Briskness Index (BI) was found to be 24.76 (Ispahani Blender's Choice) and the lowest value was found to be 21.88 (Tetley-Premium) and followed the sequence as Ispahani-Blender's

Choice $>$ Lipton-Taaza $>$ Finlay-Premium $>$ HRC-Clevedon $>\mathrm{T}$ etley-Premium. The normal range of briskness index proposed for South Indian teas is 12.5 to 22.5. But, when it drops below 17.5, the liquors tend to have a harsh taste and when it exceeds 17.5 the liquor gets brisker [24]. Briskness index values of all the brand teas in the present study were between 22 and 25 . So it can be said that liquors of all the 
studied brands were rich in briskness.

The results shown in Fig. 3 reveal that maximum Colour Index was estimated to be 10.94 (HRC-Clevedon) and minimum was estimated to be 8.75 (Tetley-Premium) and showed the sequence as HRC-Clevedon> Ispahani-Blender's

Choice $>$ Lipton-Taaza $>$ Finlay-Premium $>$ Tetley-Premium. For better tea, the colour index should be between 5 and 11 in order to have the liquor balanced with colour and briskness. If the colour index value cross 11 , then the tea lacks colour and when it falls below 5 , the liquor will be coloured and flat with low briskness [20]. In the present study, the colour index values for all the brands were between 8 and 11 . So the colour indices of all the studied brand teas were up to the mark in respect to Bangladesh tea standard.

It is also evident from the result as presented in Fig. 1 that in respect to total amount of active components (Caffeine, TPC, TF, TR and HPS) so far studied in this experiment Lipton-Taaza tea $(40.38 \%)$ was found to be superior among the five different brands whilst the lowest amount was determined in Tetley-Premium tea $(25.61 \%)$ and consequently followed the sequence as Lipton-Taaza $>$ Finlay-Premium >Ispahani-Blender's Choice $>$ HRC-Clevedon $>$ Tetley. It is reported that the Finlay tea was found to be superior over the ten major marketed brands of tea of Bangladesh in concerning the qualitative status and ranked the brands as follows: Finlay $>$ HRC $>$ Lipton $>$ Acme $>$ Ispahani $>$ Seylon $>$ Pran $>$ T etley $>$ Fresh $>$ Kazi \& Kazi [21].

The tea plant accumulates fluoride as it grows, with mature leaves containing the most fluoride. When tea is harvested, the older leaves are used to produce lower quality, stronger teas such as economy teas. The bud and newer top leaves are used in the higher grade and speciality tea products. It is suggested that an adult consume no more than $3 \mathrm{mg}$ of fluoride a day but four cups of cheap supermarket tea provide $6 \mathrm{mg}$ of the substance. Excessive intake of fluoride can cause a variety of health problems including joint pain, muscle weakness, osteoporosis, brittle teeth, kidney problems and has even been linked to cancer [33]. So, in case of taking tea, consumers should be conscious about the quality of tea whether it is higher or lower graded and cheap tea bags should not be preferred to save money.

\section{Conclusions}

The present study concludes that tea of Lipton-Taaza, Finlay-Premium, Ispahani-Blender Choice and HRC-Clevedon brands might have been harvested in peak plucking period (August-October) and that of Tetley tea in decreasing plucking period (November-January). The Caffeine, TPC, TF, TR, HPS, and TLC contents of five studied brands of tea were medium in quantity but comparable with qualitative standard of Bangladesh tea. Above all, the plucking standard was not maintained properly and there might have been followed the standard of a bud with four leaves or downward plucking. It can further be concluded that in respect to qualitative status so far studied Lipton-Taaza tea was found to be superior among the five different brands but all of the brands could be defined as medium quality tea.

\section{REFERENCES}

[1] C. Pasha and G. Reddy. Nutritional and medicinal improvement of black tea by yeast fermentation. Food Chemistry. Vol. 89, 449-453, 2005.

[2] A. E. Bradfield. Some recent developments in the chemistry of tea. Chem. Ind. Vol. 65, 242-246, 1946.

[3] I. S. Bhatia. Biochemical investigations in relation to tea manufacture. Two and A Bud. Vol. 11, No. 1. 8-15, 1964

[4] M. A. Bokuchava and N. I. Skobeleva. The chemistry and biochemistry of tea and tea manufacture. Adv. Food Res. Vol. 17, 215-292, 1969.

[5] K. Chow and I. Kramer. All the Tea in China. China Books and Period. Inc., San Francisco. 1990.

[6] H. Okumura, M. Ichitani, T. Takihara and K. Kunimoto. Effect of cyclodextrins on the thermal epimerization of tea catechins. Food Sci. Technol. Res. Vol. 14, No. 1, 83-88, 2008.

[7] J. Peterson, J. Dwyer, S. Bhagwat, D. Haytowitz, J. Holden, A L. Eldridge, G. Beecher, J. Aladesanmi. Major flavonoids in dry tea. Journal of Food Composition and Analysis. Vol. 18, 487-501, 2005.

[8] G. W. Sanderson. The chemistry of tea and tea manufacturing. In: Runeckles, V.C. and Tso TC; Recent Advances in Phytochemistry: structural and functional aspects of phytochemistry. Vol. 5, 247-316, 1972.

[9] W. X. Xiao. Polyphenols and the metabolism in tea trees. In: Wang ZN. (Ed). Tea Biochemistry. 2nd edition. Agric. Academic Press, Beijing. 86-118, 1994.

[10] R. G. Bailey, H. E. Nursten and I. McDowell. Use of an HPLC photodiode-array detector in a study of the nature of a black tea liquor. J. Sci. Food Agric. Vol. 52, 509-525, 1990.

[11] Z. Ding, S. Kuhr and U. H. Engelhardt. Influence of catechins and theaflavins on the astringent taste of black tea brews. Z. Lebensm. Unters. Forsch. Vol. 195, 108-111, 1992.

[12] I. McDowell, R. G. Bailey and G. Howard. The flavonol glycosides of black tea. J. Sci. Food Agric. Vol. 53, 411-414, 1990.

[13] E. A. H. Roberts. The phenolic substances of manufactured tea and their origin as enzymic oxidation products in fermentation. J. Sci. Food Agric. Vol. 9, 212-216, 1958a.

[14] E. A. H. Roberts. The chemistry of tea manufacture. J. Sci. Food Agric. Vol. 9, 381-390, 1958b.

[15] E. A. H. Roberts. Economic Importance of flavonoid substances in tea fermentation. Chemistry of flavonoid compounds (Geissman, TA. ed) Pergamon press, London. 468-512, 1962.

[16] A. G. Brown, C. P. Falshaw, E. Haslam, A. Holmes and W. D. Ollis. The constitution of theaflavin. Tetrah. Lett. Vol. 11, 1193-1204, 1966.

[17] Y. Takino, M. Ferretti, V. Flanagan, M. Gianturco and M. Vogel. The structure of theaflavin, a polyphenol of black tea. Tetrah. Lett. Vol. 45, 4019-4025, 1965. 
[18] Balentine DA, Wiseman SA and Bouwens LCM; . The chemistry of tea flavonoids. Crit. Rev. Food Sci. Nutr., 1997; 37(8): 693-704, 1997.

[19] H. N. Graham. Green tea composition, consumption, and polyphenol chemistry. Prev. Med. Vol. 21, 334-350, 1992.

[20] T. Muthumani and R. S. S. Kumar. Influence of fermentation time on the development of compounds responsible for quality in black tea. Journal of Food Chemistry. Vol. 101(2007), 98-102, 2006.

[21] K. M. M. Alam, M. S. Uddin, M. A. M. Chowdhury and M. A. Motalib. Qualitative evaluation of ten major marketed brands of tea in Bangladesh. Plant Archives (International Journal of Plant Research). Vol. 11, No. 1, 173-177, 2011.

[22] Annon. Determination of Caffeine. Bangladesh Standard Specification. (BDSS). 808, 1974. 20-21, 1975.

[23] M. M. Molla. Study on the nature of polyphenols in BTRI clones. Tea Journal of Bangladesh. Vol. 17, 20-25, 1981.

[24] S. N. S. Thanaraj and R. Seshadri. Polyphenol oxidase activity and polyphenol content of black tea. Journal of the Science of Food and Agriculture. Vol. 51, 60-61, 1990.

[25] S. Ramaswamy. Improving tea Quality in South India. UPASI Tea Scientific Department Bulletin. Vol. 41, 12-24, 1986.

[26] R. G. D .Steel, J. H. Torrie, D. A. Dickie. Principles and Procedures of Statistics. 3rd. Edn. Mc Graw Hill Book Co. New York, USA, 1997.
[27] D. A. Balentine, M. E. Harbowy, H. N. Graham. Tea: the Plant and its Manufacture; Chemistry and Consumption of the Beverage. 1998.

[28] M. A. Choudhury. Nutritional Properties of Tea. The Bangladesh Journal of Scientific Research. Special issue, 45-54, 1990.

[29] M. A. M. Chowdhury and K. M. M. Alam. Screening for qualitative and quantitative status of green tea in ten clonal agro-types cultured at BTRISS, ODAHLEA, Bangladesh. Proceedings of 2001 international conference on O-CHA (tea) culture and science, Shizuoka, Japan. session-II (production), 41-45. 2001

[30] K. M. M. Alam and M. A. M. Chowdhury; Dynamics of caffeine and polyphenol in pluckable tea shoots of ten clonal agrotypes cultured at BTRISS, Odahlea, Bangladesh. International Journal of Tea Science. Vol.6, No.4, 37-43, 2007.

[31] J. B. Cloughly. Annual Report of the Tea Research Foundation of Central Africa (Report of the Biochemistry section.). 87-98, 1981.

[32] M. R. Karim, M. A. Choudhury, A. K. M. G. Kibria and M. H. Rahman. Crude fibre and TF-TR contents in Bangladesh tea and their industrial significance. Tea J. of Bangladesh. Vol.36, No.1\&2, 39-46, 2000.

[33] L. Chan, A. Mehra, S. Saikat and P. Lynch. Human exposure assessment of fluoride from tea (Camellia sinensisL.): A UK based issue? Food Research International. Vol. 51, No. 2, 564-570, 2013. 